\title{
Airway obstruction due to massive lingual oedema following cleft palate surgery
}

The Pierre Robin syndrome consists of micrognathia, pseudo-macroglossia, glossoptosis and a high arched or cleft palale. Difficult intubation of the trachea and associated abnormalities such as congenital heart disease are well known complications of this syndrome. Intraoral surgery (such as cleft palate repair and palatoplasty) can also be technically difficult for the surgeon resulting in prolonged retraction on the tongue with a mouth gag to provide adequate surgical exposure. We report a case where massive lingual oedema following a cleft palate repair resulted in life-threatening airway obstruction.

\section{Key words}

COMPLICATIONS: lingual oedema, airway obstruction; SURGERY: prolonged; EQUIPMENT: mouth retractor.

Surgical procedures involving the airway, particularly in paediatric patients, can result in the patient having compromised respiration. This may either be as a result of the surgery or the increased hazards associated with anaesthesia when airway access is shared with the surgeon.

We report a case of massive lingual oedema which likely was the result of prolonged surgical retraction on the tongue.

\section{Case report}

A white female infant was delivered after a full term gestation with Apgar scores of six and eight at one

From the Oregon Health Sciences University, Department of Anesthesiology, 3181 S.W. Sam Jackson Park Road, Portland, OR 97201.

Address correspondence to: Dr. Kingston. and five minutes respectively. The child required immediate tracheal intubation because of increasing respiratory distress. At this time the infant was diagnosed as having features characteristic of the Pierre Robin syndrome, namely micrognathia, a large tongue and a cleft palate defect. After 24 hours, the endotracheal tube was removed without further evidence of airway obstruction. At the age of four weeks, the child needed resection of a choledochal cyst. At this time the trachea was intubated without difficulty.

At 18 months of age, the child was scheduled for cleft palate repair. The patient had been in good health except for failure to thrive, being at less than the tenth percentile for her predicted weight. On examination, micrognathia and large bilateral soft palate clefts were noted. The tongue and pharynx appeared normal, and the child had no obvious respiratory difficulty. After attaching EKG electrodes and a blood pressure cuff, anaesthesia was induced with halothane and oxygen. An intravenous infusion was started, and once it was established that the lungs could be easily ventilated, succinylcholine was given intravenously, facilitating the insertion of an endotracheal tube which was taped in the midline.

A Dingman retractor extending to the base of the tongue was placed to provide surgical exposure. A Wardill-Kilner procedure which involves repair and setback of palate was undertaken. ${ }^{1}$ This proved to be technically difficult and the procedure continued for four hours, without release of the tongue retractor. When the surgical procedure was completed, a tongue suture was placed to allow forward traction on the tongue should this become necessary.

The child was extubated in the operating room when awake. Immediately after extubation, inter- 


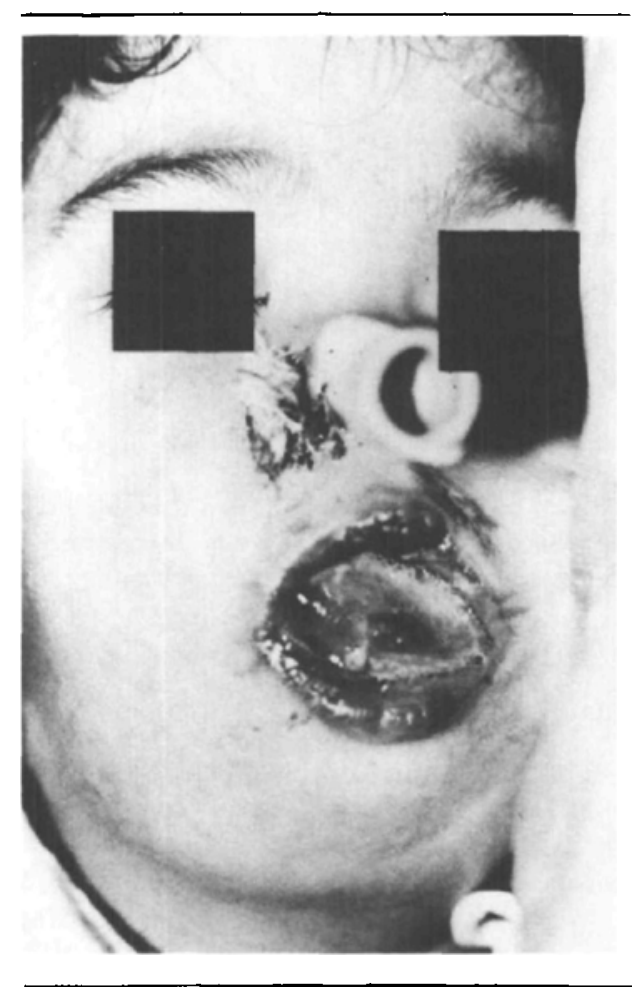

FIGURE Oedema of the tongue 24 hours after cleft palate repair. A nasal tracheal tube is in place.

mittent tachypnoea and inspiratory stridor were noticed. Initially, this was relieved with anterior displacement of the tongue and mandible, but later required an oral airway in addition. Within five to ten minutes ( 30 minutes after release of the tongue retractor), sublingual and lingual oedema was evident. The child became cyanotic, with increased respiratory efforts. A blind nasal intubation was performed with difficulty but resulted in immediate relief of the respiratory obstruction. Following intubation, the child appeared well oxygenated and was transferred to the intensive care unit where she continued to breath spontaneously.

Over the next 36 hours, the lingual and sublingual oedema worsened despite high-dose steroid therapy (Figure 1). At this time the protruding swollen tongue precluded any examination of the surgical repair. On the sixth postoperative day, the oedema had resolved sufficiently to allow extubation of the trachea. Examination now showed a small fistula in the palatal repair which did not require further surgical revision.

\section{Discussion}

The micrognathia and glossoptosis of the Pierre Robin syndrome present severe problems of airway management. ${ }^{2}$ Frequently (as in our case) respiratory distress is present immediately after birth and may require urgent endotracheal intubation or nursing in the prone position.

When patients with Pierre Robin syndrome require repair of the palatal cleft, endotracheal intubation as well as surgical access are often technically challenging. Anaesthesia and postoperative care may be complicated by other congenital defects as well as malnutrition and anaemia resulting from feeding difficulties. These children commonly present for surgical correction of the palatal cleft between 12 and 18 months of age. ${ }^{3}$

In a prospective study, postoperative airway obstruction was reported with cleft palate surgery, but appeared to be more common when a pharyngeal flap was fashioned in addition to the palatal repair. ${ }^{4.5}$ Schettler also demonstrated that the incidence of airway obstruction increased ten-fold if the cleft palate repair required longer than two hours, as compared with those which took less than two hours. ${ }^{6}$ The increased risk is probably associated with difficulties of repair and subsequent tissue oedema.

If the cleft palate repair is technically difficult, the retraction to obtain adequate exposure may be prolonged and can be associated with excessive pressure on the base of the tongue. It is also a common practice to suspend the tongue retractor on a Mayo stand which keeps the patient's head in a hyperextended position. Both the retraction and hyperextension cause impairment of arterial flow into and/or venous drainage from the tongue. In our case, continuous compression of the base of the tongue over a four-hour period may have resulted in the massive lingual and sublingual oedema.

Since the oral cavity is small in a child with Pierre Robin syndrome, a massively swollen tongue can occlude the oropharynx posterially. In addition, the nasopharynx can be obstructed both by oedema and from surgical closure of the cleft palate and upward protrusion of the oedematous tongue. Emergency reinsertion of a nasotracheal tube establishes an adequate airway, but may be technically difficult or 
impossible, necessitating tracheostomy. Urgent tracheal intubation may cause disruption of the palatal repair or free nasopharyngeal bleeding. We were fortunate in that these complications were not encountered in our patient.

During intraoral surgical procedures requiring use of a mechanical tongue retractor, we recommend that the anaesthetist inform the surgeon of the period of time the retractor has been in position. If the repair of the defect has been prolonged, especially when the repair has included a pharyngoplasty, there should be a high index of suspicion of airway compromise. Since it is highly likely that the oedema demonstrated by our patient was due to the protracted presence of a mechanical tongue retractor, we will recommend that in our institution the tongue retractor should be released for five minutes in each hour it is used. Patients having cleft palate surgery will then be prospectively studied to determine whether lingual oedema still occurs in spite of this precaution. When surgery has been prolonged, it may be preferable to keep the child intubated in the postoperative recovery area rather than having to attempt rapid, blind nasotracheal intubation to secure an adequate airway. We recommend frequent assessment of both the tongue size and the degree of laryngeal oedema by assessment of the air leak around the tube. If an air leak is not evident when $25 \mathrm{~cm}$ of water pressure is applied to the tube with a "T" piece, or the lingual oedema prevents examination of the pharynx, the child should remain intubated and be managed in an intensive care unit with humidified inspired gas until such a time as a leak can be demonstrated. Intravenous dexamethasone may be useful for treatment of oedema. Once tracheal extubation is thought to be possible, this should be undertaken either in the ICU or the operating room where the equipment for rapid reintubation, as well as expert medical and nursing care, are available.

\section{Acknowledgements}

The authors thank Dr. John Branford for his help with this case, and Carol Johnson for her secretarial assistance in preparing this manuscript.

\section{References}

1 Calnan JS. V-Y Pushback palatorrhaphy. Cleft lip and palate. Little, Brown and Co., 1971.

2 Steward DJ. Plastic and reconstructive surgery. In: Manual of Pediatric Surgery. Churchill-Livingstone. 1979.

3 Lindsay WK. Surgical repair of cleft palate. Clinics in Plastic Surgery 1975; 2: 309-18.

4 Wray C, Dann J, Holtmann B. A comparison of three technics of palatorrhaphy: In-hospital morbidity. Cleft Palate J 1979; 16: 42-5.

5 Jackson $P$, Whitaker LA, Randall P. Airway hazards associated with pharyngeal llap in patients who have the Pierre-Robin syndrome. Plast Reconstr Surg 1976; 58: 184-6.

6 Schettler $D$. Intra- and post-operative complications in surgical repair of clefts in infancy. J Maxillofac Surg 1973; 1: 40-4.

\section{Résumé}

Le syndrome de Pierre Robin consiste en une micrognathie, une pseudo-macroglossie, une glossoptose et une voûte du palais à arc élevé ou un bec de lièvre. L'intubation de la trachée difficile et les anomalies associées, tel que les maladies cardiaques congénitales, sont des complications bien connues de ce syndrome. Une chirurgie buccale (comme une correction d'un bec de lièvre et palatoplastie ou staphyloplastie peut être techniquement difficile pour le chirurgien craignam une rérraction prolongée de la langue avec un ouvre-bouche afin de créer une exposition chirurgicale adéquate. On rapporte un cas d'oedème massif de la langue après une réparation d'un bec de lièvre créant une obstruction potentiellement mortelle des voies aériennes. 